\title{
Discrimination of internal derangement of temporomandibular joint by lateral cephalometric analysis
}

\author{
Sug-Joon Ahn, ${ }^{a}$ Seung-Hak Baek, ${ }^{a}$ Tae-Woo Kim, ${ }^{b}$ and Dong-Seok Nahm ${ }^{b}$ \\ Seoul, Korea
}

Introduction: The purposes of this study were to analyze the progress of internal derangement (ID) of the temporomandibular joint (TMJ) and to find critical yardsticks that can be used during lateral cephalometric analysis to identify subjects with potential ID. Methods: The sample consisted of 134 women whose primary complaints were malocclusions. They were divided into 5 groups based on the results of magnetic resonance imaging of bilateral TMJs: bilateral normal disc position, unilateral disc displacement with reduction (DDR) and contralateral normal disc position, bilateral DDR, unilateral DDR and contralateral disc displacement without reduction (DDNR), and bilateral DDNR. Thirty-six cephalometric variables from their lateral cephalograms were analyzed with 1-way ANOVA and discriminant analysis to determine the key factors in identifying subjects with TMJ ID. Results: Backward positioning of the mandible, clockwise rotation of the mandible, proclination of the mandibular incisors, and increase in overjet intensified gradually with the progression of TMJ ID, and the subjects with bilateral DDNR showed the greatest changes in dentofacial morphology. Stepwise variable selection in discriminant analysis identified the following 2 variables: mandibular incisor to Frankfort horizontal plane angle and overjet. Discriminant analysis resulted in the correct classification of $79.1 \%$ of the subjects and showed that those with smaller mandibular incisor to Frankfort horizontal plane angles and larger overjets had high possibilities of TMJ ID. Conclusions: This study suggests that some cephalometric variables can be used as an auxiliary diagnostic tool to help identify patients with potential TMJ ID. (Am J Orthod Dentofacial Orthop 2006;130:331-9)

$\mathbf{I}$ nternal derangement (ID), the most common type of temporomandibular disorder, is characterized by progressive displacement of the articular disc. ${ }^{1-3}$ By using magnetic resonance imaging (MRI) to determine disc position, the prevalences of ID are approximately $30 \%$ in asymptomatic adults and $84 \%$ in symptomatic patients. ${ }^{4-7}$ All forms of ID are more prevalent in female than male patients. ${ }^{8}$ ID can alter the functional environment and normal adaptive capacity of the temporomandibular joint (TMJ); this can be associated with a change in dentofacial morphology. ${ }^{9,10}$ However, the cause-and-effect relationship between TMJ ID and altered craniofacial morphology is still unknown.

From the Dental Research Institute and Department of Orthodontics, College of Dentistry, Seoul National University, Seoul, Korea.

${ }^{\mathrm{a}}$ Assistant professor.

brofessor.

Reprint requests to: Dong-Seok Nahm, Department of Orthodontics, College of Dentistry, Seoul National University, 28-22 Yunkeun-Dong, Chongro-Ku, Seoul 110-768, Korea (ROK);

e-mail,dsnahm@snu.ac.kr.

This study was supported by a grant of the Korea Health 21 R\&D Project, Ministry of Health \& Welfare, Republic of Korea (03-PJ1-PG1-CH09-0001).

Submitted, November 2004; revised and accepted, February 2005. $0889-5406 / \$ 32.00$

Copyright (C) 2006 by the American Association of Orthodontists. doi:10.1016/j.ajodo.2005.02.019
Currently, various methods and devices are used to diagnose ID of the TMJ. Among them, MRI is a sensitive method of identifying TMJ disc displacement and is the only method that directly depicts the disc in either a normal or an abnormal position. ${ }^{11,12}$ In addition, it also offers several advantages, eg, noninvasiveness, minimal pain, minimal risk potential, and no ionizing-radiation exposure. ${ }^{13}$ However, MRI is too expensive to recommend routinely for identifying TMJ ID, particularly in orthodontic patients.

Recent studies suggested the possibility of using lateral cephalometric variables to identify patients with TMJ ID. ${ }^{14-18}$ Decreased posterior facial height, decreased effective mandibular length, and backward rotation of the mandible were reported to be distinctive features of those with TMJ ID. However, most studies focused on finding an association between TMJ ID and dentofacial morphology. The relationship between dentofacial changes and the progress of TMJ ID, particularly the initial dentofacial change in the early stages of TMJ ID, is still unclear. In addition, critical yardsticks that can differentiate subjects with TMJ ID from those with normal TMJs have not been presented. If it were possible to identify patients with TMJ ID by 
using routine orthodontic records, such as lateral cephalograms, this would provide clear advantages for diagnosis and treatment planning, as well as patient education.

This study was undertaken to evaluate the changes in dentofacial morphology according to the progress of TMJ ID from its initial stage and to find key factors to discriminate patients with potential ID from those with normal TMJs by using lateral cephalometric analysis.

\section{MATERIAL AND METHODS}

The sample consisted of women over the age of 17 . Men were not included to avoid skewing the measurements with sex-related size differences. No subject had undergone previous orthodontic treatment or had previously been diagnosed with juvenile rheumatoid arthritis. Each subject had a primary complaint of a malocclusion, and routine lateral cephalograms were taken. Irrespective of the TMJ status, all subjects consented to bilateral high-resolution MRIs in the sagittal (open and closed) and coronal (closed) planes to evaluate the TMJs. The MRIs were obtained by using Signa Horison (GE, Waukesha, Wis) operating at $1.5 \mathrm{~T}$ and a unilateral 3-in surface receiver coil (GE). Initially, the axial scout images were obtained at the level of the TMJs to identify the long axes of the condyles. Nonorthogonal sagittal sections were obtained perpendicular to the condyles, and nonorthogonal coronal oblique sections were also obtained. Closed-mouth images were obtained at maximum dental intercuspation; open-mouth images were taken at maximum unassisted vertical mandibular opening by using a Burnett bidirectional TMJ device (Medrad, Pittsburgh, Pa). T1-weighted 600/12 (repetition time [TR] ms/echo time [TE] ms) and proton-density 4000/14 (TR ms/TE ms) pulse sequences were performed in the sagittal plane by using slices of 3-mm thickness, a 10-cm field of view, 2 excitations, and an image matrix of $254 \times 192$ pixels. T1-weighted 500/12 (TR ms/TE ms) pulse sequence was performed in the coronal plane under the same conditions.

An orthodontist (T-W.K.) and a radiologist with TMJ MRI experience interpreted the images. According to previous criteria, TMJ disc position was divided into 3 categories: normal disc position, disc displacement with reduction (DDR), and disc displacement without reduction (DDNR) ${ }^{14}$ The position and shape of the disc were evaluated carefully according to classification criteria for the disc position (Fig 1). Some images lacking the clarity necessary for diagnosis of TMJ ID were rejected.

A total of 140 subjects were originally selected and analyzed. The MRIs identified 41 patients with bilaterally normal disc positions (group 1). There were 21 patients with unilateral DDR and normal disc position in the contralateral TMJ (group 2). Twenty-seven patients had bilateral DDR (group 3), and 15 patients were identified with unilateral DDR and DDNR in the contralateral TMJ (group 4). There were 30 patients who had bilateral DDNR (group 5). Only 6 patients had 1 DDNR and the other joint with a normal disc position; they were excluded because of the low sample size. The remaining sample included 134 women (Table I).

One investigator (S-J.A.) traced all cephalograms. The tracings were digitized by using a digitizer interfaced with a desktop computer. Twenty-one landmarks were digitized on each radiograph, from which 36 variables were calculated. For convenience of analysis, these variables were subdivided into 6 categories: cranial base relationships, vertical skeletal relationships, maxillary and mandibular skeletal relationships, size and form of the mandible, dental relationships, and soft-tissue relationships. The positions of the landmarks are shown in Figure 2, and their measurements are shown in Figures 3, 4, and 5. The differences among the 5 groups were tested by using 1-way analysis of variance (ANOVA) (Table II). The Duncan multiple comparisons were done at a significance level of $\alpha=$ 0.05 (Table III).

To find the critical factors that can discriminate subjects with TMJ ID from those with normal TMJs, all subjects were classified again into 2 groups according to TMJ ID: a normal TMJ group and a TMJ ID group. The normal TMJ group consisted of the patients with bilaterally normal TMJs (the 41 subjects in the group 1), and those with ID in at least 1 TMJ were placed in the TMJ ID group (the 93 subjects in groups 2, 3, 4, and 5). Discriminant analysis with stepwise entry of variables was designed, and the classification power of the selected discriminant function was examined.

To test the magnitude of the measurement error in this study, the lateral cephalograms of 15 randomly selected patients were measured again. By using Dahlberg's formula, ${ }^{19}$ the errors ranged from 0.22 to 0.85 $\mathrm{mm}$ for the linear measurements and from $0.21^{\circ}$ to $0.96^{\circ}$ for the angular measurements.

\section{RESULTS}

Table II shows the differences in the dentofacial variables among the 5 groups. The results showed that 23 of the 36 cephalometric variables had statistically significant differences. Generally, the variables related to the mandible showed statistically significant differences. The statistical differences were mainly due to the discrepancy between the subjects in group 5 (bilateral DDNR) and the other 4 groups (Table III).

In the cranial base relationships, no variables had 

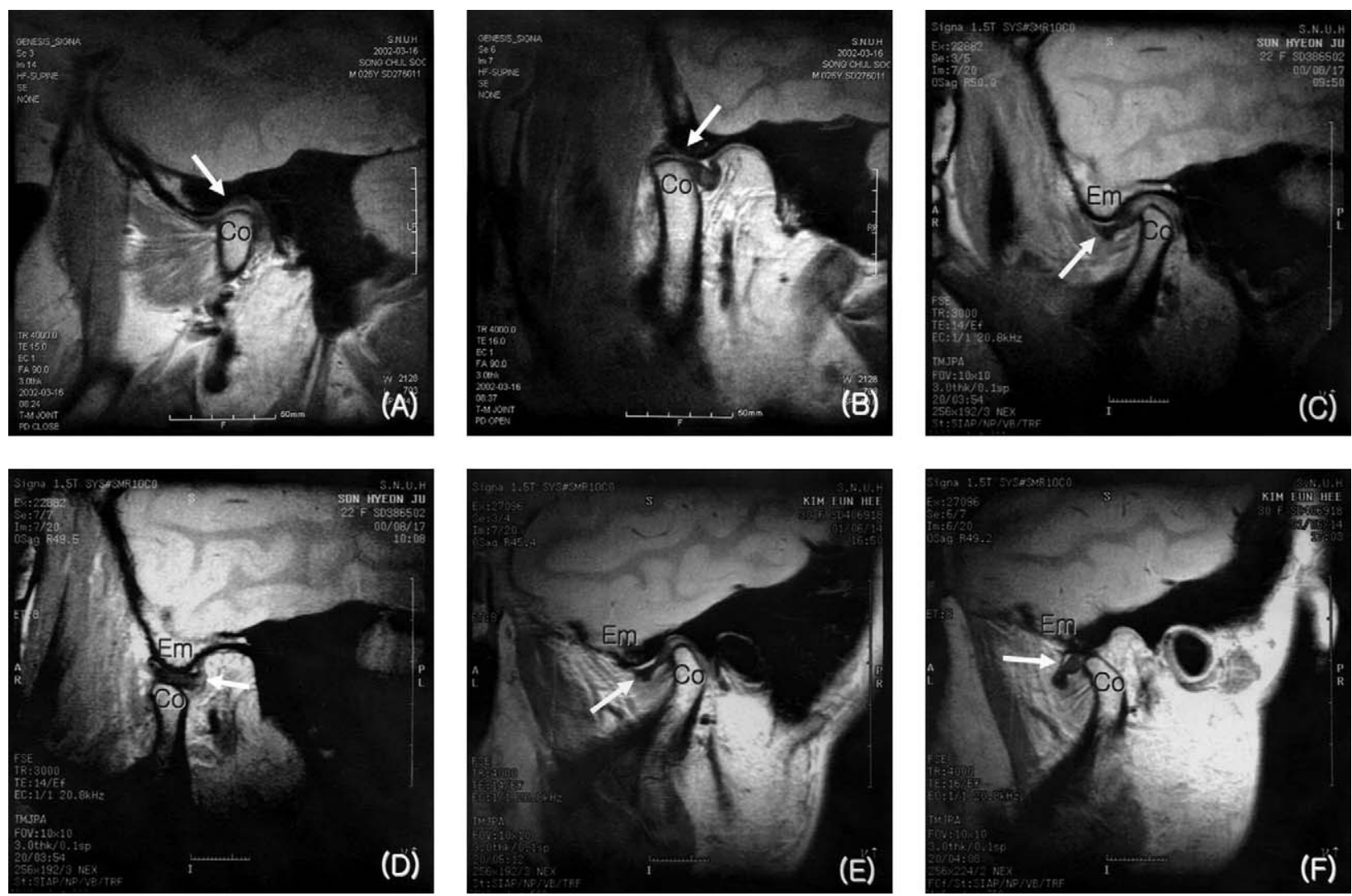

Fig 1. Normal TMJ disc position to condyle in A, closed-mouth and $\mathbf{B}$, open-mouth sagittal images. Intermediate zone of disc (arrow) was interposed between condyle (Co) in both positions. DDR to condyle in C, closed-mouth and D, open-mouth sagittal images. Disc (arrow) was anteriorly displaced relative to posterior slope of articular eminence $(E m)$ and head of condyle (Co). However, disc was reduced on mouth opening. DDNR to condyle in $\mathbf{E}$, closed-mouth and $\mathbf{F}$, open-mouth sagittal images. Disc (arrow) was anteriorly displaced relative to posterior slope of articular eminence $(\mathrm{Em})$ and head of condyle $(\mathrm{Co})$, but without reduction of disc on mouth opening.

Table I. Comparison of mean ages and age ranges of subjects with bilaterally normal disc position (group 1), with 1 DDR and other joint with normal disc position (group 2), with bilateral DDR (group 3), with unilateral DDR and DDNR in contralateral TMJ (group 4), and with bilateral DDNR (group 5)

\begin{tabular}{|c|c|c|c|c|c|c|}
\hline & $\begin{array}{c}\text { Group } 1 \\
n=41\end{array}$ & $\begin{array}{c}\text { Group } 2 \\
n=21\end{array}$ & $\begin{array}{c}\text { Group } 3 \\
n=27\end{array}$ & $\begin{array}{c}\text { Group } 4 \\
n=15\end{array}$ & $\begin{array}{c}\text { Group } 5 \\
n=30\end{array}$ & $\begin{array}{c}\text { Total } \\
n=134\end{array}$ \\
\hline Age (y) & $22.1 \pm 3.7$ & $25.5 \pm 7.6$ & $24.0 \pm 4.9$ & $23.1 \pm 3.5$ & $24.3 \pm 5.5$ & $23.6 \pm 5.2$ \\
\hline Range (y) & $17.4-32.2$ & $17.5-43.7$ & $18.2-37.7$ & 19.1-30.7 & $17.0-38.9$ & $17.0-43.7$ \\
\hline
\end{tabular}

statistically significant differences. Of the variables that represent maxillomandibular relationships, differences in $\mathrm{SNB}$ angle, $\mathrm{N}$ perpendicular to pogonion, facial convexity, ANB angle, and Wits appraisal showed statistical significance, whereas $\mathrm{N}$ perpendicular to Point A and SNA angle had no statistical significance (Table II). The subjects with TMJ ID had small SNB angles and $\mathrm{N}$ perpendicular to pogonion, and large facial convexity, ANB angles, and Wits appraisals; this means a skeletal Class II pattern with retrognathic mandible. The changes were more intensive as TMJ ID progressed to severe. Multiple comparisons showed that the differences shown were mainly between groups 1 and 2 or 3 or 4 , and between groups 2 or 3 and 5 (Table III). This means that the mandible tends to move distally as TMJ ID progresses.

Regarding vertical skeletal relationships, differences in FMA, $\mathrm{SN}$ to mandibular plane angle, 


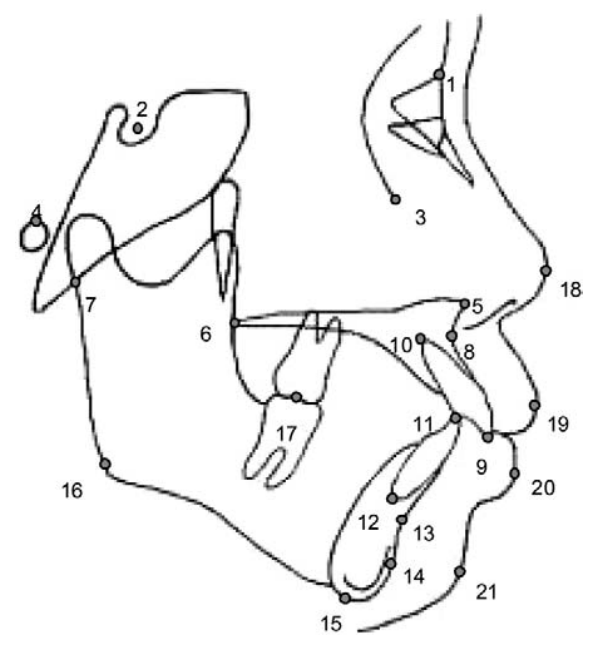

Fig 2. Landmarks used in study: 1, nasion; 2, sella; 3, orbitale; 4, porion; 5, anterior nasal spine; 6, posterior nasal spine; 7, articulare; 8 , Point $A ; 9$, incisal end of maxillary incisor; 10, apex of maxillary incisor; 11, incisal end of mandibular incisor; 12, apex of mandibular incisor; 13, Point B; 14, pogonion; 15, menton; 16, gonion; 17, articulation of maxillary and mandibular molars; 18, pronasale; 19, upper lip; 20, lower lip; 21, soft-tissue pogonion.

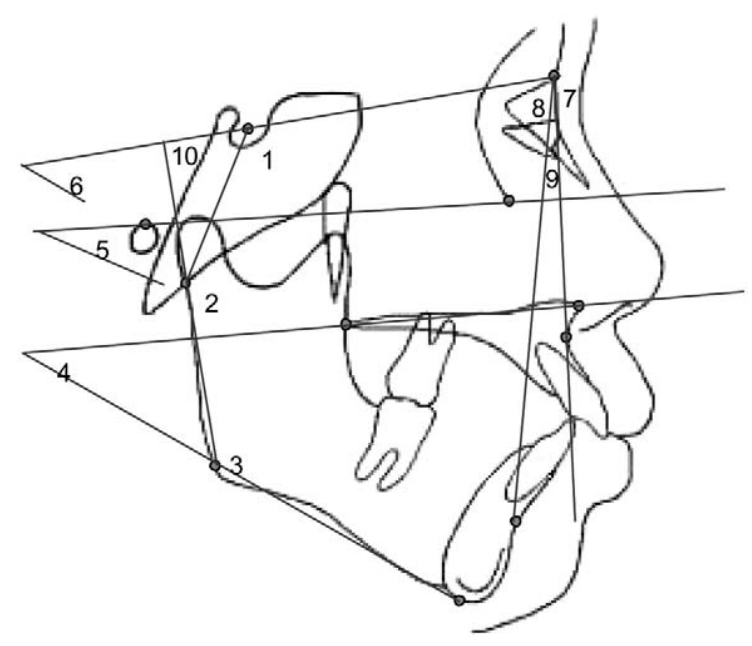

Fig 3. Angular measurements used in study: 1, saddle angle (Na-S-Ar); 2, articular angle (S-Ar-Go); 3, gonial angle (Ar-Go-Me); 4, maxillomandibular plane angle; 5, $\mathrm{FH}$ to mandibular plane angle; 6, SN to mandibular plane angle; 7, SNA angle; 8, SNB angle; 9, ANB angle; 10 , ramus inclination (N-S to Ar-Go).

maxillomandibular plane angle, occlusal plane to mandibular plane angle, total posterior facial height, and facial height ratio (total anterior facial height to total posterior facial height ratio) were statistically

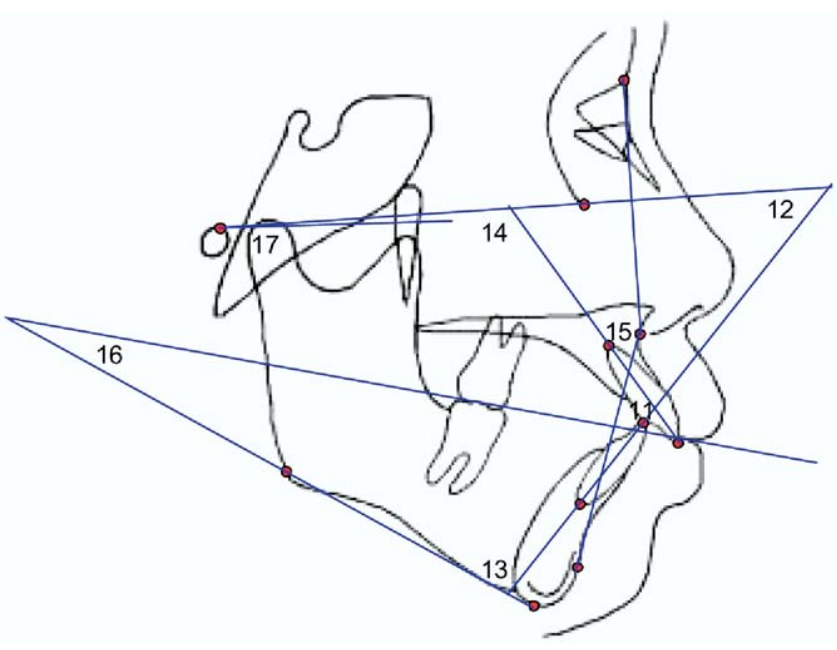

Fig 4. Angular measurements used in study (continued): 11, interincisal angle; 12, mandibular incisor to $\mathrm{FH}$ plane angle; 13, mandibular incisor to mandibular plane angle; 14, maxillary incisor to FH plane; 15, facial convexity; 16, occlusal plane to mandibular plane angle; $17, \mathrm{FH}$ to palatal plane angle.

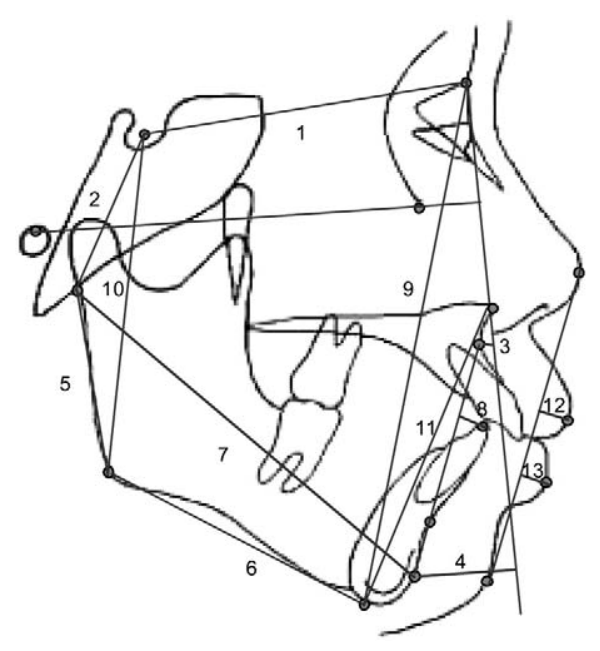

Fig 5. Linear measurements used in study: 1, anterior cranial base length (S-N); 2, posterior cranial base length (S-Ar); 3, N perpendicular to Point A; 4, N perpendicular to pogonion; 5, ramus height (Ar-Go); 6, mandibular body length (Go-Me); 7, effective mandibular length (Ar-Pog); 8, L1 to A-Pog; 9, total anterior facial height ( $\mathrm{N}-\mathrm{Me})$; 10 , total posterior facial height (S-Go); 11, lower anterior facial height (ANS-Me); 12, upper lip thickness (Ricketts' E-line); 13, lower lip thickness (Ricketts' E-line).

significant (Table II). However, these variables apparently did not detect the differences among the 5 groups, and all differences shown were only between group 5 and the other 4 groups. This means that a backward 
Table II. Comparison of cephalometric variables of subjects with bilaterally normal disc position (group 1), with 1 DDR and other joint with normal disc position (group 2), with bilateral DDR (group 3), with unilateral DDR and DDNR in contralateral TMJ (group 4), and with bilateral DDNR (group 5)

\begin{tabular}{|c|c|c|c|c|c|c|}
\hline Variables & $\begin{array}{l}\text { Group } 1 \\
(n=41)\end{array}$ & $\begin{array}{l}\text { Group } 2 \\
(n=21)\end{array}$ & $\begin{array}{l}\text { Group } 3 \\
(n=27)\end{array}$ & $\begin{array}{l}\text { Group } 4 \\
(n=15)\end{array}$ & $\begin{array}{l}\text { Group } 5 \\
(n=30)\end{array}$ & Significance \\
\hline \multicolumn{7}{|l|}{ Cranial base relationships } \\
\hline Anterior cranial base length $(\mathrm{S}-\mathrm{N})(\mathrm{mm})$ & $67.7 \pm 2.9$ & $67.9 \pm 2.5$ & $67.7 \pm 3.0$ & $66.9 \pm 2.4$ & $66.6 \pm 2.7$ & NS \\
\hline Posterior cranial base length (S-Ar) (mm) & $34.9 \pm 3.5$ & $34.7 \pm 3.1$ & $36.1 \pm 2.4$ & $36.7 \pm 2.7$ & $33.6 \pm 4.7$ & NS \\
\hline Saddle angle $(\mathrm{N}-\mathrm{S}-\mathrm{Ar})\left(^{\circ}\right)$ & $123.6 \pm 5.3$ & $125.5 \pm 3.9$ & $124.7 \pm 5.6$ & $124.2 \pm 5.3$ & $122.2 \pm 4.9$ & NS \\
\hline \multicolumn{7}{|l|}{ Maxillomandibular relationships } \\
\hline SNA angle $\left({ }^{\circ}\right)$ & $81.6 \pm 3.1$ & $81.0 \pm 3.7$ & $81.3 \pm 2.9$ & $81.2 \pm 2.8$ & $81.9 \pm 3.7$ & NS \\
\hline SNB angle $\left({ }^{\circ}\right)$ & $80.3 \pm 4.8$ & $77.4 \pm 3.3$ & $76.8 \pm 3.3$ & $76.5 \pm 3.0$ & $74.2 \pm 4.3$ & $\$$ \\
\hline $\mathrm{N}$ perpendicular to Point $\mathrm{A}(\mathrm{mm})$ & $2.3 \pm 2.6$ & $2.5 \pm 3.5$ & $1.9 \pm 2.5$ & $0.6 \pm 2.9$ & $1.5 \pm 3.4$ & NS \\
\hline $\mathrm{N}$ perpendicular to pogonion $(\mathrm{mm})$ & $2.2 \pm 10.5$ & $-1.9 \pm 7.0$ & $-5.3 \pm 7.2$ & $-8.3 \pm 5.8$ & $-14.1 \pm 8.1$ & 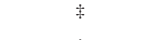 \\
\hline Facial convexity $(\mathrm{N}-\mathrm{A}-\mathrm{Pog})\left({ }^{\circ}\right)$ & $2.0 \pm 9.7$ & $6.7 \pm 6.7$ & $8.6 \pm 4.8$ & $9.0 \pm 4.9$ & $15.8 \pm 6.3$ & $\$$ \\
\hline ANB angle $\left({ }^{\circ}\right)$ & $1.2 \pm 4.3$ & $3.7 \pm 3.4$ & $4.5 \pm 2.1$ & $4.7 \pm 2.3$ & $7.6 \pm 2.4$ & 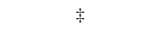 \\
\hline Wits appraisal (mm) & $-6.7 \pm 6.5$ & $-3.1 \pm 5.9$ & $-1.0 \pm 3.3$ & $-1.6 \pm 3.6$ & $1.7 \pm 3.1$ & $\$$ \\
\hline \multicolumn{7}{|l|}{ Vertical skeletal relationships } \\
\hline FMA $\left({ }^{\circ}\right)$ & $28.9 \pm 5.9$ & $28.6 \pm 5.9$ & $30.2 \pm 6.6$ & $31.7 \pm 4.9$ & $37.2 \pm 7.9$ & $\$$ \\
\hline SN to mandibular plane angle $\left(^{\circ}\right)$ & $39.3 \pm 6.4$ & $39.9 \pm 6.9$ & $40.6 \pm 6.0$ & $41.0 \pm 5.0$ & $46.6 \pm 8.8$ & $¥$ \\
\hline FH to palatal plane angle $\left({ }^{\circ}\right)$ & $0.6 \pm 3.1$ & $-0.5 \pm 2.7$ & $-0.2 \pm 3.1$ & $0.6 \pm 2.5$ & $0.1 \pm 3.8$ & NS \\
\hline \multicolumn{7}{|l|}{ Maxillomandibular plane angle } \\
\hline$(\mathrm{ANS}-\mathrm{PNS} / \mathrm{Go}-\mathrm{Me})\left({ }^{\circ}\right)$ & $28.3 \pm 5.5$ & $29.1 \pm 6.1$ & $30.4 \pm 7.5$ & $31.0 \pm 6.1$ & $37.1 \pm 7.8$ & $\$$ \\
\hline Occlusal plane to mandibular plane angle $\left(^{\circ}\right)$ & $20.0 \pm 4.5$ & $18.7 \pm 5.2$ & $20.0 \pm 5.4$ & $19.3 \pm 3.5$ & $23.0 \pm 4.8$ & $*$ \\
\hline Total anterior facial height $(\mathrm{N}-\mathrm{Me})(\mathrm{mm})$ & $132.7 \pm 5.5$ & $130.9 \pm 6.1$ & $133.2 \pm 6.1$ & $131.6 \pm 5.4$ & $132.6 \pm 6.3$ & NS \\
\hline Total posterior facial height (S-Go) (mm) & $83.3 \pm 6.1$ & $82.3 \pm 5.6$ & $83.4 \pm 6.5$ & $81.7 \pm 3.5$ & $77.6 \pm 7.6$ & $\dagger$ \\
\hline Lower anterior facial height (ANS-Me) (mm) & $76.1 \pm 5.1$ & $75.5 \pm 4.6$ & $76.7 \pm 5.4$ & $76.4 \pm 5.6$ & $78.9 \pm 5.4$ & NS \\
\hline $\begin{array}{l}\text { Total anterior facial height/total posterior facial } \\
\text { height }(\%)\end{array}$ & $62.9 \pm 5.1$ & $63.1 \pm 4.8$ & $63.0 \pm 4.3$ & $62.4 \pm 3.3$ & $59.2 \pm 5.7$ & $\dagger$ \\
\hline $\begin{array}{l}\text { Lower anterior facial height/total anterior facial } \\
\text { height }(\%)\end{array}$ & $55.1 \pm 2.4$ & $54.6 \pm 2.1$ & $54.4 \pm 2.9$ & $54.0 \pm 2.4$ & $54.1 \pm 2.9$ & NS \\
\hline \multicolumn{7}{|l|}{ Size and form of mandible } \\
\hline Ramus height (Ar-Go) (mm) & $51.3 \pm 4.8$ & $50.2 \pm 4.1$ & $49.5 \pm 5.9$ & $46.7 \pm 4.1$ & $45.1 \pm 4.5$ & * \\
\hline Ramus inclination (SN to Ar-Go) & $94.9 \pm 6.9$ & $97.1 \pm 4.8$ & $99.8 \pm 6.7$ & $101.0 \pm 4.8$ & $104.5 \pm 5.8$ & 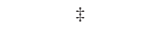 \\
\hline Mandibular body length (Go-Me) (mm) & $77.5 \pm 4.9$ & $74.5 \pm 4.4$ & $75.8 \pm 4.6$ & $75.5 \pm 3.7$ & $73.3 \pm 5.2$ & $\dagger$ \\
\hline Effective mandibular length (Ar-Pog) (mm) & $115.4 \pm 8.1$ & $111.1 \pm 5.8$ & $111.0 \pm 6.8$ & $107.4 \pm 4.1$ & $104.3 \pm 5.6$ & $\ddagger$ \\
\hline Anterior cranial base/mandibular body length (\%) & $115.4 \pm 8.6$ & $109.6 \pm 6.0$ & $112.2 \pm 6.8$ & $112.9 \pm 8.1$ & $110.2 \pm 7.2$ & NS \\
\hline Gonial angle $(\mathrm{Ar}-\mathrm{Go}-\mathrm{Me})\left({ }^{\circ}\right)$ & $124.4 \pm 6.8$ & $122.8 \pm 6.3$ & $120.8 \pm 8.2$ & $120.0 \pm 6.2$ & $122.1 \pm 7.9$ & NS \\
\hline Articular angle $(\mathrm{S}-\mathrm{Ar}-\mathrm{Go})\left(^{\circ}\right)$ & $151.3 \pm 8.8$ & $151.6 \pm 5.8$ & $155.1 \pm 7.9$ & $156.8 \pm 6.4$ & $162.3 \pm 7.7$ & $\neq$ \\
\hline \multicolumn{7}{|l|}{ Dental relationships } \\
\hline Maxillary incisor to $\mathrm{FH}$ plane $\left({ }^{\circ}\right)$ & $120.8 \pm 7.2$ & $116.3 \pm 10.1$ & $119.9 \pm 7.5$ & $118.0 \pm 6.9$ & $115.8 \pm 8.4$ & NS \\
\hline Mandibular incisor to $\mathrm{FH}$ plane $\left({ }^{\circ}\right)$ & $62.1 \pm 12.4$ & $56.8 \pm 7.8$ & $54.2 \pm 7.0$ & $51.0 \pm 5.8$ & $46.7 \pm 5.3$ & $\neq$ \\
\hline Interincisal angle $\left({ }^{\circ}\right)$ & $121.4 \pm 11.4$ & $120.6 \pm 14.8$ & $114.3 \pm 11.7$ & $113.0 \pm 8.1$ & $110.9 \pm 9.7$ & $\dagger$ \\
\hline Mandibular incisor to mandibular plane angle $\left(^{\circ}\right)$ & $90.0 \pm 11.3$ & $94.6 \pm 8.3$ & $95.6 \pm 7.2$ & $97.4 \pm 5.4$ & $96.2 \pm 6.4$ & $\dagger$ \\
\hline Mandibular incisor to A-Pog (mm) & $7.1 \pm 4.7$ & $4.5 \pm 5.1$ & $3.1 \pm 3.6$ & $2.2 \pm 3.5$ & $0.1 \pm 4.2$ & $\neq$ \\
\hline Overbite (mm) & $-1.0 \pm 2.7$ & $0.1 \pm 3.0$ & $-0.3 \pm 3.1$ & $-0.5 \pm 3.0$ & $-0.7 \pm 2.8$ & NS \\
\hline Overjet $(\mathrm{mm})$ & $1.2 \pm 3.2$ & $3.2 \pm 3.8$ & $4.9 \pm 2.0$ & $5.0 \pm 3.1$ & $6.8 \pm 2.1$ & $\ddagger$ \\
\hline \multicolumn{7}{|l|}{ Soft-tissue relationships } \\
\hline Ricketts' E-line to upper lip (mm) & $-1.4 \pm 3.3$ & $-0.2 \pm 2.5$ & $1.4 \pm 1.9$ & $1.5 \pm 2.0$ & $3.8 \pm 3.1$ & \# \\
\hline Ricketts' E-line to lower lip (mm) & $1.7 \pm 2.7$ & $1.8 \pm 3.1$ & $2.7 \pm 2.3$ & $3.6 \pm 2.8$ & $5.5 \pm 3.4$ & $\ddagger$ \\
\hline
\end{tabular}

NS, Not significant; $* P<.05 ;{ }^{\dagger} P<.01 ;{ }^{\ddagger} P<.001$.

rotation of the mandible appears when TMJ ID progresses to bilateral DDNR, the terminal stage of TMJ ID.

In the size and form of the mandible, differences in ramus height, ramus inclination, mandibular body length, effective mandibular length, and articular angle were statistically significant (Table II), whereas anterior cranial base to mandibular body length ratio and gonial angle were not statistically significant. Ramus inclination discriminated the differences among the 5 groups relatively well compared with the other variables (Table III). As TMJ ID progresses, ramus height, mandibular body length, and effective mandibular length tended to decrease gradually, but ramus inclination and articular angle tended 
to increase gradually. However, the statistical differences became apparent when TMJ ID progressed to bilateral DDR (group 3), except for effective mandibular length.

In the dental variables, differences in mandibular incisor to Frankfort horizontal (FH) plane, interincisal angle, mandibular incisor to mandibular plane angle, mandibular incisor to A-Pog, and overjet were statistically significant. The results showed that the mandibular incisors proclined and overjet increased as TMJ ID progressed. The variables associated with the position of the mandibular incisors well discriminated the difference in dentofacial morphology at an early stage of TMJ ID—ie, the difference between unilateral DDR and contralateral normal TMJ and bilateral normal TMJs. Among these variables, overjet discriminated the differences in the 5 groups comparatively well (Table III).

Differences in protrusion of the upper and lower lips were statistically significant among the 5 groups in the soft-tissue relationships. The protrusion of the upper and lower lips tended to be more prominent as TMJ ID progressed to a more severe condition. However, the statistically significant differences appeared least when TMJ ID progressed to bilateral DDR (group 3).

Discriminant analysis with stepwise entry of the variables selected 2 variables: mandibular incisor to $\mathrm{FH}$ plane angle and overjet. Unstandardized discriminant function coefficients led to the following equation, which gives the individual scores for assigning a new patient to either the normal TMJ group or the TMJ ID group (Table IV):

$$
\begin{aligned}
& \text { Individual score }=-0.06 \\
& \times(\text { mandibular incisor to FH plane angle })+0.216 \\
& \times(\text { overjet })+2.8731
\end{aligned}
$$

The critical score between the normal TMJ group and TMJ ID group was 0 . This means that a woman with a score lower than 0 has a normal TMJ. However, a woman with a score higher than 0 is expected to have TMJ ID on at least 1 side. The percentage of correctly classified subjects was $79.1 \%$ (Table IV). Fourteen patients in the normal TMJ group (34.1\%) and 14 in the TMJ ID group (15.1\%) were misclassified.

\section{DISCUSSION}

TMJ ID is the most common TMJ arthropathy and is characterized by several stages of dysfunction that involve the condyle-disc relationship. ${ }^{20,21}$ Generally, the 2 types of derangements of the condyle-disc complex are well known: DDR and DDNR. These conditions can progress to DDNR by way of DDR. ${ }^{20}$
This study showed that progress of TMJ ID is strongly associated with changes in dentofacial morphology, particularly mandibular morphology (Table II). Decrease in the height of the ramus, decrease in the effective size of the mandible, and backward rotation of the ramus were associated with progress of TMJ ID. These changes in mandibular morphology might influence changes in maxillomandibular relationships, manifesting in decreases in SNB and N perpendicular to pogonion, and increases in ANB angle, facial convexity, and Wits appraisal as TMJ ID progresses. The changes in the dental and soft-tissue relationships also can be explained by changes in the mandibular morphology. Increases in the proclination of the mandibular incisors, overjet, and protrusion of the upper and lower lips as TMJ ID progresses can be explained by backward rotation of the mandible and compensatory forward movement of the mandibular incisors related to decreased size of the ramus and the mandible.

Vertical skeletal relationships also changed with the progress of TMJ ID. FMA, SN to mandibular plane, maxillomandibular plane angle, and total anterior facial height to total posterior height ratio increased significantly in the subjects with bilateral DDNR (group 5) compared with those in the other 4 groups, but there was no statistical significance among the other 4 groups (Table II). The changes in the vertical skeletal relationships were due to decreases in posterior facial height, because differences in the measurements of anterior vertical dimensions of the face did not show any significant differences (Tables II and III). However, the vertical skeletal relationships changed significantly when TMJ ID progressed to bilateral DDNR, the terminal stage of TMJ ID. This indicates that the vertical change occurs after the horizontal change in dentofacial morphology according to the progress of TMJ ID.

This study showed that the amount of change in dentofacial morphology gradually increased, as TMJ ID progressed to severe. Although the difference was slight, SNB angle, $\mathrm{N}$ perpendicular to pogonion, facial convexity, ANB angle, Wits appraisal, effective mandibular length, mandibular incisor to FH plane angle, mandibular incisor to mandibular plane angle, and overjet showed statistically significant differences between the subjects with bilateral normal TMJs (group 1) and those with unilateral normal TMJ and contralateral DDR (group 2) (Table III). This indicates that dentofacial morphology starts to change during the initial stage of TMJ ID. However, more evident changes in dentofacial morphology were found when TMJ ID progressed to bilateral DDR (group 3). Most variables with statistical significance showed even more dif- 
Table III. Duncan multiple range test for group comparison

\begin{tabular}{ll}
\hline Variable & Homogeneous subsets with statistically significant difference $(\mathrm{P}<.05)^{*}$ \\
\hline SNB angle & $(1>2,3,4>5)$ \\
N perpendicular to pogonion & $(1>2,3>5),(1>4)$ \\
Facial convexity (N-A-Pog) & $(1<2,3,4<5)$ \\
ANB angle & $(1<2,3,4<5)$ \\
Wits appraisal & $(1<2,3,4,5),(2,4<5)$ \\
FMA & $(1,2,3,4<5)$ \\
SN to mandibular plane angle & $(1,2,3,4<5)$ \\
Maxillomandibular plane angle (ANS-PNS/Go-Me) & $(1,2,3,4<5)$ \\
Occlusal plane to mandibular plane angle & $(1,2,3,4<5)$ \\
Total posterior facial height (S-Go) & $(1,2,3,4>5)$ \\
Total anterior facial height/total posterior facial height & $(1,2,3,4>5)$ \\
Ramus height (Ar-Go) & $(1,2,3>4,5)$ \\
Ramus inclination (SN to Ar-Go) & $(1<3,4,5),(2<4,5),(3<5)$ \\
Mandibular body length (Go-Me) & $(1>5)$ \\
Effective mandibular length (Ar-Pog) & $(1<2,3<5),(1<4)$ \\
Articular angle (S-Ar-Go) & $(1,2<4,5),(3<5)$ \\
Mandibular incisor to FH plane & $(1>2,3,4,5),(2>4,5),(3>5)$ \\
Interincisal angle & $(1>3,4,5),(2>4,5)$ \\
Mandibular incisor to mandibular plane angle & $(1<2,3,4,5)$ \\
Mandibular incisor to A-Pog & $(1>2,3,4,5),(2,3>5)$ \\
Overjet (mm) & $(1<2<3,4,5),(3<5)$ \\
Ricketts' E-line to upper lip (mm) & $(1,2<3,4<5)$ \\
Ricketts' E-line to lower lip (mm) & $(1,2<4,5)(3<5)$ \\
&
\end{tabular}

*Group 1, Bilateral normal disc position; group 2, 1 DDR and other joint with normal disc position; group 3, bilateral DDR; group 4, unilateral DDR and DDNR in contralateral side; group 5, bilateral DDNR.

ferences in the subjects with bilateral DDR compared with those with bilaterally normal TMJs (Table III). The backward rotation of the ramus, decreased effective length of the mandible, and the proclination of the mandibular incisors were more evident at this stage.

All changes became more intensive as TMJ ID progressed. The greatest changes were apparent in the subjects with bilateral DDNR (group 5), and the statistical differences were mainly due to the discrepancy between those with bilateral DDNR and those in the other 4 groups (Table III). Our results are consistent with previous studies that showed a relationship between dentofacial morphology and progress of TMJ ID, although their samples did not include subjects with unilateral TMJ ID. ${ }^{14-18}$ These results strongly suggest that disc displacement is a potential risk factor that can influence dentofacial morphology.

In this study, discriminant analysis was used to categorize the subjects into the normal TMJ and the TMJ ID groups. Stepwise variable selection selected 2 variables: mandibular incisor to $\mathrm{FH}$ plane angle and overjet. The discriminant analysis showed that the subjects with TMJ ID had smaller mandibular incisor to FH plane angles and larger overjets than those with bilaterally normal TMJs. These 2 variables were efficient in identifying subjects with potential ID according to the progress of TMJ ID (Table III).
Table IV. Classification results of discriminant function

\begin{tabular}{lcll}
\hline & & \multicolumn{2}{c}{ Predicted membership } \\
\cline { 3 - 4 } Actual group & Subjects $(n)$ & \multicolumn{1}{c}{2} & \multicolumn{1}{c}{2} \\
\hline Normal TMJ* & 41 & 27 & 14 \\
& & $65.9 \%$ & $34.1 \%$ \\
TMJ ID $^{\dagger}$ & 93 & 14 & 79 \\
& & $15.1 \%$ & $84.9 \%$
\end{tabular}

Percentage of original grouped cases correctly classified: $79.1 \%$.

*Normal TMJ, subjects with bilaterally normal TMJs.

${ }^{\dagger} T M J I D$, subjects with TMJ ID on at least 1 side.

The first variable extracted from the discriminant analysis was mandibular incisor to FH plane angle. The subjects with TMJ ID had smaller mandibular incisor to FH plane angle then those with bilaterally normal TMJs (Table II). This might be due to the relative proclination of the mandibular incisors associated with backward rotation of the ramus and the mandible as TMJ ID progresses. This is also partly explained by the compensatory proclination of the mandibular incisors related to backward position of the ramus and the mandible. As a second variable, overjet was selected. The subjects with TMJ ID had large overjets compared with those with normal TMJs. Similar to mandibular incisor to FH plane angle, this might be because the 
subjects with TMJ ID had retrognathic mandibles associated with decreased size and backward rotation of the ramus and the mandible.

As a result, the smaller mandibular incisor to $\mathrm{FH}$ plane angle and larger overjet seem to be strongly associated with a skeletal Class II pattern with vertical dysplasia. The subjects with TMJ ID might not maintain normal overjet ranges despite compensatory proclination of the mandibular incisors because of dramatic changes in the ramus and the mandible. This is consistent with previous studies that showed that TMJ disc displacement was associated with severe Class II vertical dysplasia. ${ }^{14-16}$

The classification power of this model was $79.1 \%$ for each subject. Discriminant analysis had the highest accuracy in predicting TMJ ID (93.3\%), although the analysis showed relatively low accuracy in predicting normal TMJs $(65.9 \%)$.

Discriminant analysis was attempted again to discriminate the differences among the original 5 groups, which represent progressive stages of TMJ ID. However, this resulted in relatively few correct classifications. Only $49.4 \%$ of the original group was correctly classified (data not shown). The reason for the low accuracy in predicting TMJ ID might be due to the wide range of individual variations and the complex interplay of dental and skeletal compensations associated with TMJ ID. This also can be explained by the limitations of lateral cephalometric analysis. Because TMJ ID can change condylar morphology on the affected side, subjects with TMJ ID with greater severity on the unilateral side might have facial asymmetry. Lateral cephalograms cannot accurately account for asymmetries, because the right and left landmarks were averaged. This can make it difficult to discriminate the subjects in group 2 (unilateral normal TMJ and contralateral DDR) or group 4 (unilateral DDR and contralateral DDNR) and the other groups. Nevertheless, the accuracy of TMJ ID stage diagnosis using lateral cephalometric analysis is comparable with that of clinical examination, which is reported to be too variable to acquire meaningful conclusions. ${ }^{22,23}$

It is important to identify patients with potential ID before orthodontic treatment, because they can develop TMJ symptoms during orthodontic treatment or after surgery for skeletal deformities irrespective of their treatment. ${ }^{2-26}$ MRI is the best method to identify patients with TMJ ID, but it is too expensive to check patients routinely. This study showed that the initial change associated with TMJ ID can be detected in lateral cephalograms by careful examination. However, these initial facial changes might be overlooked by a clinician unfamiliar with dentofacial changes associated with disc displacement, because the amount of initial change is not enough to be detected.

Recently, some posteroanterior cephalometric and panoramic variables, eg, mandibular and ramus vertical asymmetry, decreased condylar height, and distally inclined condylar head, were also reported to be associated with TMJ ID. ${ }^{27-29}$ Therefore, it is possible to diagnose TMJ ID in orthodontic patients, based on information from the patient's history and physical examination and evidence from routine orthodontic records, such as lateral and posteroanterior cephalograms and panoramic radiographs.

\section{CONCLUSIONS}

In this study, we investigated the relationship between dentofacial change and progress of TMJ ID to find key factors that can identify subjects with TMJ ID. A total of 134 women were classified by using TMJ MRI, and their lateral cephalometric variables were analyzed by using 1-way ANOVA and discriminant analysis. The results showed that posteriorly rotated mandibular ramus, steep mandibular plane, small mandible, protrusion of the mandibular incisors, large overjet, and protrusion of the upper and lower lips were associated with the progress of TMJ ID. Dentofacial changes became more severe as ID progressed gradually to bilateral DDNR, the terminal stage of TMJ ID. Mandibular incisor to FH plane angle and overjet were selected in the discriminant analysis, and the discriminant function had $79.1 \%$ of classification power. This study suggests that a quantitative evaluation of the lateral cephalograms can provide valuable information on the initial dentofacial changes associated with TMJ ID.

\section{REFERENCES}

1. Farrar WB, McCarty WL. Inferior joint space arthrography and characteristics of condylar paths in internal derangement of the TMJ. J Prosthet Dent 1979;41:548-55.

2. Dolwick MF, Katzberg RW, Helms CA. Internal derangement of the temporomandibular joint. Fact or fiction? J Prosth Dent 1983;49:415-8

3. Eversole LR, Machado L. Temporomandibular joint internal derangements and associated neuromuscular disorders. J Am Dent Assoc 1985;110:69-79.

4. Kircos LT, Ortendahl DA, Mark AS, Arakawa M. Magnetic resonance imaging of the TMJ disk in asymptomatic volunteers. J Oral Maxillofac Surg 1987;45:852-4.

5. Tasaki MM, Westesson PL, Isberg AM, Ren YF, Tallents RH. Classification and prevalence of temporomandibular joint disk displacement in patients and symptom-free volunteers. Am J Orthod Dentofacial Orthop 1996;109:249-62.

6. Katzberg RW, Westesson PL, Tallents RH, Drake CM. Anatomic disorders of the temporomandibular joint disc in asymptomatic subjects. J Oral Maxillofac Surg 1996;54:147-53. 
7. Tallents RH, Katzberg RW, Murphy W, Proskin H. Magnetic resonance imaging findings in asymptomatic volunteers and symptomatic patients with temporomandibular disorders. J Prosthet Dent 1996;75:529-33.

8. Nebbe B, Major PW. Prevalence of TMJ disc displacement in a pre-orthodontic adolescent sample. Angle Orthod 2000;70:454-63.

9. Stegenga B, de Bont LG, Boering G, van Willigen JD. Tissue responses to degenerative changes in the temporomandibular joint: a review. J Oral Maxillofac Surg 1991;49:1079-88.

10. Luder HU. Articular degeneration and remodeling in human temporomandibular joints with normal and abnormal disk position. J Orofacial Pain 1993;7:391-402.

11. Westesson PL. Reliability and validity of imaging diagnosis of temporomandibular joint disorder. Adv Dent Res 1993;7:137-51.

12. Stringert HG, Worms FW. Variations in skeletal and dental patterns in patients with structural and functional alterations of the temporomandibular joint: a preliminary report. Am J Orthod 1986;89:285-97.

13. Cirbus MT, Smilack MS, Beltran J, Simon DC. Magnetic resonance imaging in confirming internal derangement of the temporomandibular joint. J Prosthet Dent 1987;57:488-94.

14. Ahn SJ, Kim TW, Nahm DS. Cephalometric keys to internal derangement of temporomandibular joint in women with Class II malocclusions. Am J Orthod Dentofacial Orthop 2004;126:486-95.

15. Nebbe B, Major PW, Prasad NG. Female adolescent facial pattern associated with TMJ disk displacement and reduction in disk length: part I. Am J Orthod Dentofacial Orthop 1999;116: 168-76.

16. Nebbe B, Major PW, Prasad NG. Male adolescent facial pattern associated with TMJ disk displacement and reduction in disk length: part II. Am J Orthod Dentofacial Orthop 1999;116:301-7.

17. Nebbe B, Major PW, Prasad NG. Adolescent female craniofacial morphology associated with advanced bilateral TMJ disk displacement. Eur J Orthod 1998;29:701-12.

18. Brand JW, Nielson KJ, Tallents RH, Nanda RS, Currier GF, Owen WL. Lateral cephalometric analysis of skeletal patterns in patients with and without internal derangement of the temporomandibular joint. Am J Orthod Dentofacial Orthop 1995;107:121-8.
19. Dahlberg G. Statistical methods for medical and biological students. New York: Interscience Publication; 1940.

20. Rasmussen OC. Description of population and progress of symptoms in a longitudinal study of temporomandibular joint arthropathy. Scand J Dent Res 1981;89:196-203.

21. Okeson JP. Diagnosis of temporomandibular disorders. In: Okeson JP, editor. Management of temporomandibular disorder and occlusion. 5th ed. St Louis: Mosby; 2003. p. 321-64.

22. Roberts CA, Katzberg RW, Tallents RH, Espeland MA, Handelman SL. Correlation of clinical parameters to the arthrographic depiction of temporomandibular joint internal derangements. Oral Surg Oral Med Oral Pathol 1988;66:32-6.

23. Anderson GC, Schiffman EL, Schellhas KP, Fricton JR. Clinical vs. arthrographic diagnosis of TMJ internal derangement. J Dent Res 1989;68:826-9.

24. Nickerson JW Jr, Moystad A. Observations on individuals with radiographic bilateral condylar remodeling. J Craniomandibular Pract 1983;1:20-37.

25. Katzberg R, Tallents RH, Hayakawa K, Miller T, Goske MJ, Wood BP. Internal derangements of the temporomandibular joint: findings in the pediatric group. Radiology 1985;154: 125-7.

26. Magnusson T, Ahlbory G, Finne K, Nethander G, Svartz K. Changes in temporomandibular joint pain and dysfunction after surgical correction of dentofacial abnormalies Int J Oral Surg 1986;15:707-14.

27. Ahn SJ, Kim TW, Lee DY, Nahm DS. Evaluation of internal derangement of the temporomandibular joint by panoramic radiographs compared with magnetic resonance imaging. Am J Orthod Dentofacial Orthop 2006;129:479-85.

28. Trpkova B, Major PW, Nebbe B, Prasad NG. Craniofacial asymmetry and temporomandibular joint internal derangement in female adolescents: a posteroanterior cephalometric study. Angle Orthod 2000;70:81-8.

29. Ahn SJ, Lee SP, Nahm DS. Relationship between temporomandibular joing internal derangement and facial asymmetry in women. Am J Orthod Dentofacial Orthop 2005;128:583-91. 